\title{
Carbon Dioxide Capture by Deep Eutectic Solvent Impregnated Sea Mango Activated Carbon
}

\author{
N.Z. Zulkurnai ${ }^{1}$, U.F. Md. Ali ${ }^{1, *}$, N. Ibrahim ${ }^{1}$, and N.S. Abdul Manan ${ }^{2}$ \\ ${ }^{1}$ School of Environmental Engineering, Universiti Malaysia Perlis, Kompleks Pusat Pengajian Jejawi \\ 3, 02600 Arau, Perlis, Malaysia \\ ${ }^{2}$ Department of Chemistry, Faculty of Science, University of Malaya, 50603 Kuala Lumpur, Malaysia
}

\begin{abstract}
The increment amount of the $\mathrm{CO}_{2}$ emission by years has become a major concern worldwide due to the global warming issue. However, the influence modification of activated carbon (AC) has given a huge revolution in $\mathrm{CO}_{2}$ adsorption capture compare to the unmodified $\mathrm{AC}$. In the present study, the Deep Eutectic Solvent (DES) modified surface $\mathrm{AC}$ was used for Carbon Dioxide $\left(\mathrm{CO}_{2}\right)$ capture in the fixed-bed column. The AC underwent pre-carbonization and carbonization processes at 519.8 ${ }^{\circ} \mathrm{C}$, respectively, with flowing of $\mathrm{CO}_{2}$ gas and then followed by impregnation with $53.75 \%$ phosphoric acid $\left(\mathrm{H}_{3} \mathrm{PO}_{4}\right)$ at $1: 2$ precursor-toactivant ratios. The prepared AC known as sea mango activated carbon (SMAC) was impregnated with DES at 1:2 solid-to-liquid ratio. The DES is composing of choline chloride and urea with ratio 1:2 choline chloride to urea. The optimum adsorption capacity of SMAC was $33.46 \mathrm{mg} \mathrm{co}_{\mathrm{co}} / \mathrm{g}_{\mathrm{sol}}$ and $39.40 \mathrm{mg}_{\mathrm{co} 2} / \mathrm{g}_{\mathrm{sol}}$ for DES modified AC (DESAC).
\end{abstract}

\section{Introduction}

The rising of greenhouse gasses emission into the atmosphere has become a great concern among the public as it is the main contributor to temperature elevation that ultimately causes global warming and climate change. Among the greenhouse gasses, carbon dioxide $\left(\mathrm{CO}_{2}\right)$ is regarded as the principal greenhouse gas that approximately contributes more than $60 \%$ to global warming [1]. The $\mathrm{CO}_{2}$ emission is mainly from the anthropogenic sources such as deforestation, transportation, and combustion of carbon emitting fuel by industrial sector and power station.

The continuous increasing of global atmospheric $\mathrm{CO}_{2}$ concentration will not only bring negatives effect on the environment but also living organisms. According to Hileman [2], the atmospheric $\mathrm{CO}_{2}$ concentration was estimated to reach about $550 \mathrm{ppm}$ by the year 2035 and leads to a temperature rise of $2^{\circ} \mathrm{C}$, which will become a threatened extinction of 15 to 40 species. However, the International Panel on Climate Change (IPPC) had estimated that the global atmospheric $\mathrm{CO}_{2}$ concentration may increase to $570 \mathrm{ppm}$ by the year 2100 that

\footnotetext{
* Corresponding author: umifazara@,unimap.edu.my
} 
will lead to the average global temperature rise of around $1.9^{\circ} \mathrm{C}$ and the average sea level rise of $3.8 \mathrm{~m}$. Therefore, immediate and sustained effort should be executed to control and reduce the $\mathrm{CO}_{2}$ level in the atmosphere.

In order to lessen the $\mathrm{CO}_{2}$ emission to the atmosphere, several convincing methods of Carbon Capture \& Storage (CCS) had been recognized such as cryogenic separation, chemical separation, membrane separation and gas adsorption method. According to Lee [3], adsorption is known as a promising method for $\mathrm{CO}_{2}$ removal as it is cost effective. Adsorption processes are normally conducted using activated carbon (AC) [4], activated alumina [5], zeolite [6] and polymeric adsorbent [7]. Based on research carried out by Duan [8] Lee [3] and El-Shafey [9], AC has the advantage to capture $\mathrm{CO}_{2}$ due to its large surface area per unit volume and submicroscopic pores. Besides, AC is also very stable in acid and basic condition and suitable for organic compound removal. In addition, it is also able to regenerate, thus its make $\mathrm{AC}$ is cost-effective adsorbent.

In terms of cost-effectiveness in the production of $\mathrm{AC}$, researchers are looking at different precursor from abundant and waste materials such as palm shell, sea mango, cocoa pods shell and rice husks. Research conducted by Siti Noraishah [10] successfully produced rice husks based $\mathrm{AC}$ and being utilized to remove $\mathrm{CO}_{2}$ generated from industrial activities.

Recently, the integration of chemicals into the $\mathrm{AC}$ has shown a convincing performance of $\mathrm{CO}_{2}$ uptakes, thus reducing the amount of $\mathrm{CO}_{2}$ released into the atmosphere compared to the typical AC without addition of any chemicals. As been measured by Saad [11] and Karousos [12], the impregnation of activated carbon with amine and ionic liquid (IL) has resulted in higher amount $\mathrm{CO}_{2}$ capture. Although the immobilization of this chemical in the $\mathrm{AC}$ assists $\mathrm{CO}_{2}$ capture, however, this sort of compound is difficult to prepare, toxic and quite expensive thus has caused it rarely used for the commercial usage [13].

Hence, in this research AC prepared from the sea mango will be chemically impregnated with a low-cost green solvent Deep Eutectic Solvent (DES) in order to improve the $\mathrm{CO}_{2}$ adsorption capacity and on the same time reduce the production cost of $\mathrm{AC}$ compare to sample impregnated with amine and IL for $\mathrm{CO}_{2}$ capture.

\section{Procedures}

\subsection{Preparation of the Sea Mango Activated Carbon}

Sea mango (Cerbera odollam) was collected around Perlis, Malaysia. In order to obtain fibrous shell, the skin and seeds were removed from the raw material. The samples were then being washed and dried in an oven for $24 \mathrm{~h}$ at $105^{\circ} \mathrm{C}$ in order to remove the moisture content. Afterward, the samples were crushed and sieved to obtain fine particles measuring $1 \mathrm{~mm}$ to $2 \mathrm{~mm}$. The raw material was then subjected to semi-carbonization in a tube furnace for $30 \mathrm{~min}$ at $200{ }^{\circ} \mathrm{C}$ by flowing of nitrogen gas. Char was subsequently impregnated with $50 \mathrm{wt} \% \mathrm{H}_{3} \mathrm{PO}_{4}$ at $1: 2$ precursor-to-activant ratio for $4 \mathrm{~h}$ and then dehydrated in the oven at $110^{\circ} \mathrm{C}$ until dryness.

The char was weighed and placed in a tube furnace until the desired temperature of $519.8{ }^{\circ} \mathrm{C}$ was reached. Activation was conducted for $2.28 \mathrm{~h}$. The samples were cooled to room temperature $\left(25^{\circ} \mathrm{C}\right)$ and washed few times with hot distilled water to remove excess $\mathrm{H}_{3} \mathrm{PO}_{4}$.

Sea Mango AC was then filtered and dried in the oven until it is completely dried. The AC samples were denoted as SMAC. 


\subsection{Preparation of the Deep Eutectic Solvent}

Choline chloride and urea (1:2) were added at $80{ }^{\circ} \mathrm{C}$ under stirring. The mixture was stirred for approximately $1 \mathrm{~h}$, and the resulting solution was clear and homogeneous.

\subsection{Functionalization of Sea Mango Activated Carbon with Deep Eutectic Solvent}

The impregnation process of SMAC was conducted with ratio 1:2 AC to DES. The sample was allowed to be impregnated in the vacuum condition for 4 hours with pressure -0.5 Bar. The impregnated sample was allowed to completely dry in an oven at $150^{\circ} \mathrm{C}$ for 8 hours. The dried DES impregnated SMAC was denoted as DESAC.

\subsection{Carbon Dioxide Adsorption}

In the adsorption testing, $\mathrm{AC}$ was added into the adsorption column. Prior the adsorption process, the sample was subjected to pure nitrogen gas in order to remove $\mathrm{CO}_{2}$ composition in the sample. This procedure is conducted in order to ensure there is no $\mathrm{CO}_{2}$ molecule attached to the surface of the sample. $15 \%$ of $\mathrm{CO}_{2}$ gas was subjected to the adsorption column using desired flow rate. The flow rate was controlled by using Aalborg, Stainless Steel Mass Flow Controller. This experiment was conducted at the atmospheric pressure and in the room temperature. The outlet of the column was connected to the Tedlar bag in order to collect exhaust gas for $\mathrm{CO}_{2}$ measurement. The $\mathrm{CO}_{2}$ in exhaust gas was measured with Geotech GA 5000 portable gas analyzer. The experimental set-up employed in this study is as shown in Fig. 1.

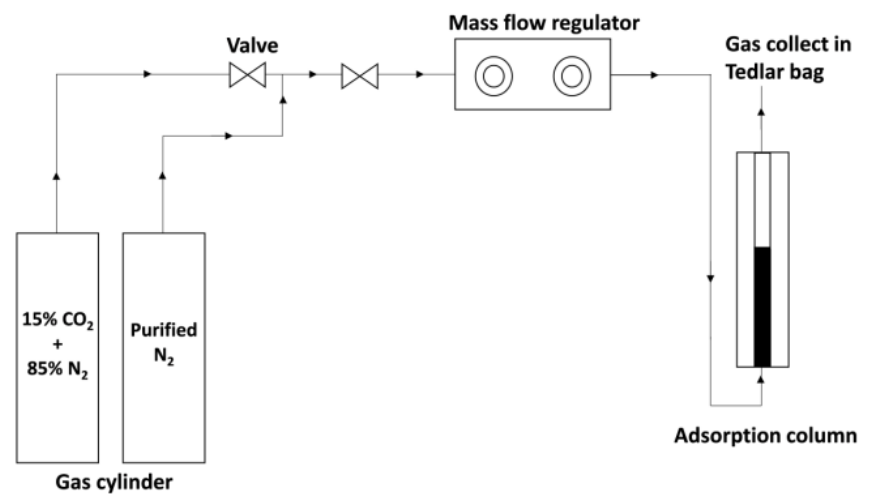

Fig. 1. Experimental setup of continuous $\mathrm{CO}_{2}$ adsorption system.

\subsubsection{Effect of different types of adsorbent on Carbon Dioxide Adsorption}

$5 \mathrm{~g}$ of different types of $\mathrm{AC}$ was weight and has been subjected to15\% of $\mathrm{CO}_{2}$ in the adsorption column. The flow rate of the gas was fixed at $10 \mathrm{ml} / \mathrm{min}$. The outlet gas was collected using the Tedlar bag and measured using Geotech GA 5000 portable gas analyzer. The $\mathrm{CO}_{2}$ adsorption capacity of the sample was obtained by using the following equation: 


$$
([v(m L / m i n) \times \rho(m g / m L) \times c(\%) \times t b(\min )]) /(w(g))
$$

$v=$ Inlet gas low rate, $\rho=\mathrm{CO}_{2}$ density at $25^{\circ} \mathrm{C}, c=$ Concentration of inlet $\mathrm{CO}_{2}, t b=$ Breakthrough time, $w=$ weight of activated carbon.

\subsubsection{Effect of adsorbent dosage on Carbon Dioxide Adsorption}

The different adsorbent dosage of DESAC was varied from $1 \mathrm{~g}$ to $5 \mathrm{~g}$ and being subjected to the $15 \%$ of $\mathrm{CO}_{2}$ gas in the adsorption column at fixed flow rate $10 \mathrm{ml} / \mathrm{min}$. The outlet sample was collected in the Tedlar bag and being tested by using GA 5000 portable gas analyzer. The $\mathrm{CO}_{2}$ adsorption capacity of each sample was calculated by using Equation 1 .

\subsection{Characterization of the Activated Carbon}

Samples have been characterizing using the standard procedure. In order to determine the total surface area, the BELSORP-Mini machine has been used. Meanwhile, surface morphology and element composition analyses were performed using JEOL JSM-6460LA Analytical Scanning Electron Microscope (SEM).

\section{Results and discussions}

\subsection{Characterization Results}

\subsubsection{BET Surface Area and Pore Characteristics}

Table 1 shows the BET surface area and characteristics for all samples. The surface area after the physiochemical treatment showing a convincing result as it is increasing significantly from $0.7820 \mathrm{~m} 2 / \mathrm{g}$ to $857.93 \mathrm{~m} 2 / \mathrm{g}$. The total pore volume of SMAC also higher compares to the raw which is $0.7166 \mathrm{~cm}^{3} / \mathrm{g}$. This result has proved that physiochemical treatment assists in the pore development of SMAC.

After impregnation with DES was conducted, the total surface area and total pore volume of DESAC was reduced to $581.23 \mathrm{~m} 2 / \mathrm{g}$ and $0.4977 \mathrm{~cm}^{3} / \mathrm{g}$ respectively. This is due to the deposition of DES, which blocks a few pores on the AC which had been proved in the SEM test. The average pore diameter for SMAC and DESAC was $3.3363 \mathrm{~nm}$ and $3.4255 \mathrm{~nm}$ respectively. It belongs to the mesopore region according to IUPAC classification [14].

Table 1. The $\mathrm{S}_{\mathrm{BET}}$ and pore structure characteristic of SMAC and DESAC.

\begin{tabular}{|c|c|c|c|c|c|}
\hline Sample & $\begin{array}{c}\mathbf{S}_{\text {BET }} \\
\left(\mathbf{m}^{2} / \mathbf{g}\right)\end{array}$ & $\begin{array}{c}\mathbf{V}_{\text {total }} \\
(\mathbf{c m} / \mathbf{g})\end{array}$ & $\begin{array}{c}\mathbf{V}_{\text {meso }} \\
\left(\mathbf{c m}^{3} / \mathbf{g}\right)\end{array}$ & $\begin{array}{c}\mathbf{V}_{\text {micro }} \\
\left(\mathbf{c m}^{\mathbf{3}} / \mathbf{g}\right)\end{array}$ & $\begin{array}{c}\mathbf{D}_{\mathbf{p}} \\
(\mathbf{n m})\end{array}$ \\
\hline Raw & 0.7920 & 0.0024 & - & - & 12.108 \\
\hline SMAC & 857.93 & 0.7166 & 0.0937 & 0.6229 & 3.3363 \\
\hline DESAC & 581.23 & 0.4977 & 0.0728 & 0.4249 & 3.4255 \\
\hline
\end{tabular}

\subsubsection{Surface Morphology}

Fig. 2 shows the surface morphology of the raw sample, SMAC, and DESAC respectively with same magnification (1000X and 5000X). From the surface morphology analysis, Fig. $2(\mathrm{a}, \mathrm{b})$ shows the physical structure of a raw sample. Evidently, the pore volume was very limited and not well developed. 
However, after physiochemical activation by using $\mathrm{H}_{3} \mathrm{PO}_{4}$ and carbonization process at $519.8^{\circ} \mathrm{C}$, the honey-comb like pore was well developed (Fig. 2 c,d), as confirmed by BET result (Table 1). The development of pore was due to the breakdown of structure in the raw due to the thermal expansion during carbonization process and the addition of the activating agent also assists in the pore development [18].

After the impregnation of the AC with the DES, a few pores in the sample seems had been clogged by the DES which has been shown in Fig 2 e and $\mathrm{f}$. It is proved that the DES was successfully attached to the sample. Consequently, the attachment of DES on the sample has reduced the pore volume in the sample which had been proving by the BET results.
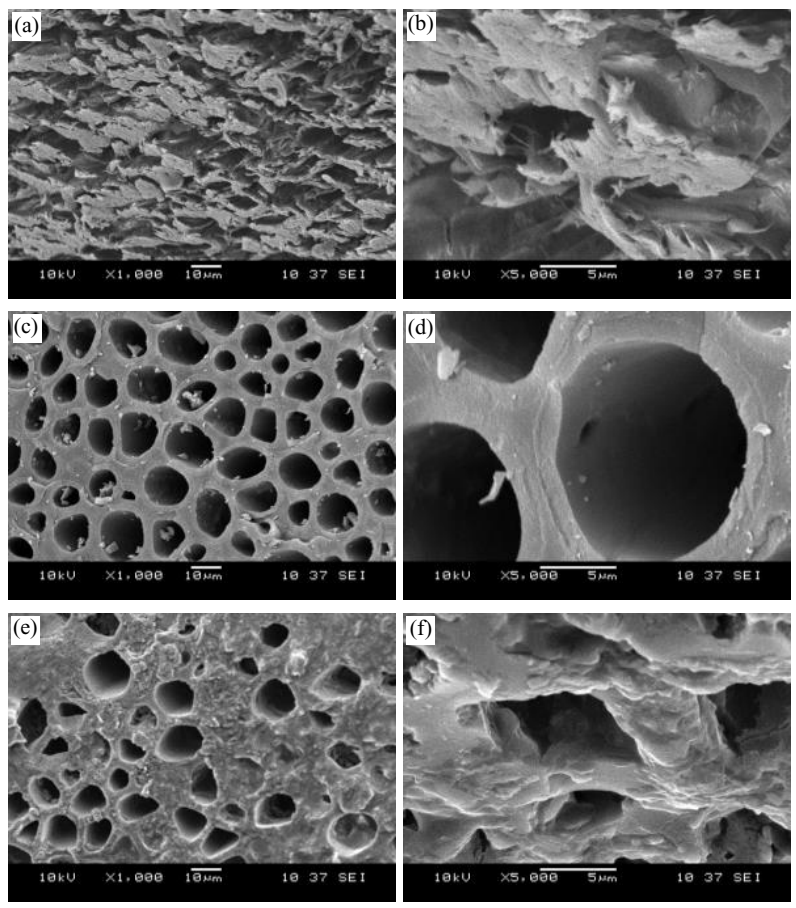

Fig. 2. SEM micrograph of raw precursor (a) $1000 \times$, (b) 5000×; SMAC (c) $1000 \times$, (d) $5000 \times$; and DESAC (e) $1000 \times$, (f) $5000 \times$.

\subsubsection{Energy-dispersive X-Ray (EDX) analysis}

Elemental analysis revealed that the element Carbon (C), Oxygen (O), Phosphorus (P), Nitrogen $(\mathrm{N})$ and Chlorine $(\mathrm{Cl})$ existed in the Raw, SMAC or DESAC. Based on table 2, the amount of $\mathrm{C}$ significantly increased in the SMAC. This finding has proved that the carbonization process assists the $\mathrm{C}$ element due to the heat supply during activation which initiates the thermal degradation process. According to the Olugbenga [19], the thermal degradation process will remove the volatile matter in the sample, thus produce a stable carbon element.

The elemental $\mathrm{P}$ also had been detected in the SMAC. The elemental $\mathrm{P}$ was believed contributed during the impregnation process using $\mathrm{H}_{3} \mathrm{PO}_{4}$. Meanwhile, the $4.01 \%$ of $\mathrm{N}$ element detected in the SMAC was believed contributed from the nitrogen purge during physiochemical activation. However, after impregnation process with DES, the amount of $\mathrm{N}$ element in the DESAC was drastically increase. It was believed that the $\mathrm{N}$ element in the 
DESAC was contributed from the urea and choline chloride of the DES. This finding has confirmed that the $\mathrm{N}$ element was successfully attached to the surface of DESAC and as a result, it will provide more actives sites for $\mathrm{CO}_{2}$ adsorption [20]. The elemental $\mathrm{Cl}$ also has been detected in the DESAC, as it was contributed from the chlorine chloride of DES during functionalization process.

Table 2. EDS elemental analysis of raw precursor, SMAC, and DESAC.

\begin{tabular}{|c|c|c|c|c|c|}
\hline \multirow{2}{*}{ Sample } & \multicolumn{5}{|c|}{ Element (wt. \%) } \\
\cline { 2 - 6 } & Carbon & Oxygen & Phosphorus & Nitrogen & Chlorine \\
\hline Raw & 48.49 & 51.51 & 0.00 & 0.00 & 0.00 \\
\hline SMAC & 75.27 & 14.62 & 6.10 & 4.01 & 0.00 \\
\hline DESAC & 48.89 & 24.45 & 0.00 & 18.39 & 8.27 \\
\hline
\end{tabular}

\subsection{Carbon Dioxide Adsorption Performance Test}

\subsubsection{Different Type of Adsorbent}

Fig. 3 shows the breakthrough time curves for SMAC and DESAC at $10 \mathrm{~mL} / \mathrm{min}$ and $5 \mathrm{~g}$ of adsorbent. Both of the breakthrough curves show a rapid $\mathrm{CO}_{2}$ uptake in the initial process and increased gradually over contact time and finally reached constant. This is because, at the initial adsorption process, all the adsorption sites of both $\mathrm{AC}$ are available for $\mathrm{CO}_{2}$ capture, however, after a certain time, the available adsorption sites has decreased and finally, all of the adsorption sites are occupied by $\mathrm{CO}_{2}$ molecule.

For SMAC, the adsorption breakthrough occurred at $60 \mathrm{~min}$, meanwhile, the DESAC breakthrough occurred at $75 \mathrm{~min}$. From the finding, it can say that the DESAC has a better adsorption performance compare to the SMAC as the $\mathrm{CO}_{2}$ adsorption capacity showing convincing results as tabulated in table 3. Highest breakthrough time obtain by DESAC was due to the $\mathrm{N}$ element in the DES which provides more actives site for $\mathrm{CO}_{2}$ capture and consequently accelerated the $\mathrm{CO}_{2}$ adsorption [21].

Table 3. Effect of different types of adsorbent dosage on $\mathrm{CO}_{2}$ adsorption.

\begin{tabular}{|c|c|c|}
\hline Sample & $\begin{array}{c}\text { Breakthrough Time } \\
\text { (second) }\end{array}$ & $\begin{array}{c}\text { Adsorption Capacity } \\
\left(\mathrm{mg}_{\mathrm{co} 2} / \mathrm{g}_{\mathrm{sol}}\right)\end{array}$ \\
\hline SMAC & 3720 & 33.46 \\
\hline DESAC & 4380 & 39.40 \\
\hline
\end{tabular}

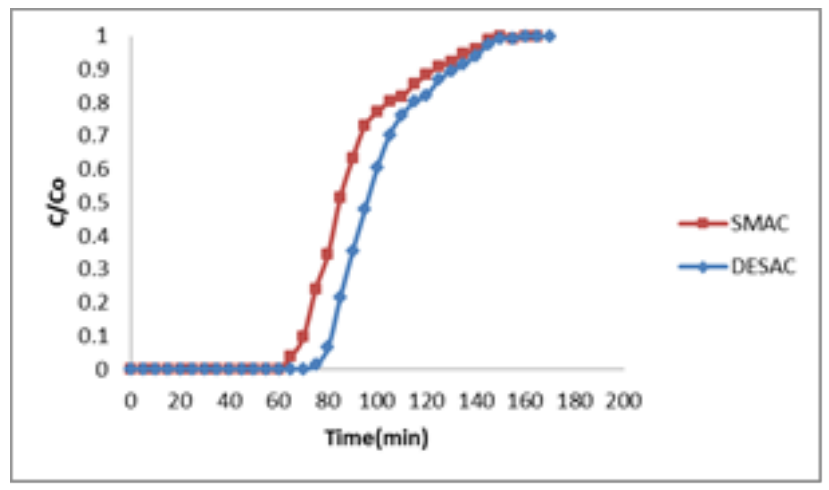

Fig. 3. Effect of different type of adsorbent dosage on $\mathrm{CO}_{2}$ adsorption. 


\subsubsection{Difference Adsorbent Dosage}

In this study, five different weight of DESAC has been tested in order to study the effect of adsorbent dosage onto the sample. Based on the table. 4, the breakthrough time has increased proportionally with increasing of adsorbent dosage. This result claims that the higher amount of adsorbent dosage will have more available active sites for $\mathrm{CO}_{2}$ capture. Consequently, the adsorption bed will need a longer time to be saturated.

However, when it's come to the adsorption capacity, increasing in adsorbent dosage has caused the adsorption capacity decreased as been shown in table 4. According to the Allesina [22], increasing adsorbent dosage by using the same adsorption column especially for the low flow rate $(10 \mathrm{ml} / \mathrm{min})$ will contribute to the higher resistance and leading to non-uniform of $\mathrm{CO}_{2}$ gas onto the sample. Consequently, this phenomenon may create channels in the adsorption bed thus reduce the chance active site being exposed to the $\mathrm{CO}_{2}$ gas which not around the channels area and reduces the adsorption capacity. This finding is in agreement with Nur Hidayah [23], which using AMP impregnated $\mathrm{AC}$ for $\mathrm{CO}_{2}$ capture.

Table 4. Effect of different types of adsorbent dosage on $\mathrm{CO}_{2}$ adsorption.

\begin{tabular}{|c|c|c|}
\hline $\begin{array}{c}\text { Sample } \\
(\mathrm{g})\end{array}$ & $\begin{array}{c}\text { Breakthrough Time } \\
(\text { second })\end{array}$ & $\begin{array}{c}\text { Adsorption Capacity } \\
\left(\mathrm{mg}_{\mathrm{c} 2} / \mathrm{g}_{\mathrm{sol}}\right)\end{array}$ \\
\hline 1 & 1920 & 86.35 \\
\hline 2 & 3000 & 67.46 \\
\hline 3 & 3600 & 53.97 \\
\hline 4 & 4020 & 45.20 \\
\hline 5 & 4380 & 39.40 \\
\hline
\end{tabular}

\section{Conclusions}

DESAC was successfully utilized as a new modification AC. The $\mathrm{CO}_{2}$ adsorption capacity of DESAC showing convincing results compares to the SMAC. Even though DESAC obtains lower BET surface area compare to SMAC, the breakthrough time of DESAC showing better results. This is due to the chemisorption action in the actives site provides by $\mathrm{N}$ element from $\mathrm{DES}$, which helps in promotion new site for more $\mathrm{CO}_{2}$ capture.

This study was financially supported by Fundamental Research Grant Scheme (FRGS 9003-00468).

\section{References}

1. D. Krishnaiah, A. Bono, S.M. Anisuzzaman, C. Joseph, B.K. Teo, J. Appl. Sci 14(23), 3142-3148 (2014)

2. B. Hileman, Chem. \& Eng. News 84, 7-8 (2006).

3. C. S. Lee, Y. L. Ong, M. K. Aroua, W.M. A. W. Daud, Chem. Eng. J. 219, 558-564 (2013)

4. S. Mohammad Saleh, W. D.Wan Mohd Ashri, H. Amirhossein, A. Shamiri, J. Anal. Appl. Pyrolysis. 89, 143-151(2010)

5. S. S. Tony, K. K. Pant, Sep. Purif. Technol. 36, 139-147 (2004)

6. K. L. Chung, S. L. Shin, C. J. Lain, C. W. Cheng, S. L Kuen, D. L. Meng, J. Hazard. Mater. 147, 997-1005 (2007)

7. D. A. Jones, T. P. Lelyveld, S. D. Mavrofidis, S. W. Kingman, N. J. Miles, Res., Conser. and Recycle. 34, 75-90 (2002)

8. X. Duan, C. Srinivasakannan, J. S. Liang, J. Taiwan Inst. Chem.Eng. 45, 1618-1627 (2014) 
9. E. I. El-Shafey, N. F. A. Syeda, A. Saleh, A. J. Haider, A. Lawati, J. of Environ. Chem. Eng. 4, 2713-2724 (2016)

10. M. R. Siti Noraishah, J. Saidatul Shima, F. A. S. Noor Asma, I. Nur Aminatulmimi, ARPN J. Eng. and Appl. Sci. 1, 1- 4 (2016)

11. H. K. Saad, M. K. Aroua, W. M. A. W. Daud, Chem. Eng. J. 183, 15-20 (2012)

12. D.S. Karousos, O. C. Vangeli, C. P. Athanasekou, A. A. Sapalidis, E. P. Kouvelos, G. E. Romanos, N. K. Kanellopoulos, Chem. Eng. J. 306, 146-154 (2016)

13. G. García, A. Santiago, U. Ruh, A. Mert, Energy Fuel 29, 2616-2644 (2015)

14. E.F. Maria, V.N. Gisel, R.B. Pablo, C. Ana Lea, Ind. Crops Proct. 62, 437-445 (2014)

15. A. Kundu, B.S. Gupta, M.A. Hashim, G. Redzwan, J. Clnr. Prod. 105, 420-427 (2015)

16. R.H. Hesas, A. Arami-Niya, W.M.A.W. Daud, J.N. Sahu, Bioresources 8(2), 29502966 (2013)

17. S. Yorgun, D.Yildiz, J. Taiwan Inst. Chem. Eng. 53, 122-131 (2015)

18. A. Mohd Azmier, A. P. Nur Azreen, S. B. Olugbenga, Wtr. Res. and Ind. 6, 18-35 (2014)

19. S. B. Olugbenga, A. Mohd Azmier, T. S. Tan, Trends in Appl. Sci. R. 6(8), 794-812 (2011)

20. M. A. Khalid, M. A. Abdul Hakim, M. Hayyana, A. Shatirah, H. Mohd Ali, Appl. Surf. Sci. 389, 216-226 (2016)

21. O. Yew Liang, Master's Thesis, Universiti Malaya, Kuala Lumpur, Malaysia (2014)

22. G. Allesina, S. Pedrazzi, P. Tartarini. Bioresource Tech. 146, 704-712 (2013)

23. A. Nur Hidayah, Master's Thesis, Universiti Malaysia Perlis, Perlis, Malaysia (2016)

24. X. Wu, J. Xu, J. Tao, New York Sci. J. 6(11), 33-37 (2013) 